Theme: Solidification / Casting

\title{
REDUCE OPERATING COSTS THROUGH WATER MANAGEMENT*
}

\author{
Henry Chumienski $i^{1}$ \\ Ricardo José da Silva ${ }^{2}$
}

\begin{abstract}
Next to the paper industry, the steel industry is a major user of water. Without an adequate and reliable source of "good" water, steel cannot be produced. The use of water has a direct impact on steel quality and on our environment. Used improperly, water can also add unnecessary costs. Used properly, water can maintain and improve steel quality, enhance our environment and control or reduce the "total cost of operation". Water needs to be more than just "wet and not lumpy". Water quality needs to be based on the end use. This paper discusses ways to manage many of the water systems. With little or no capital investment it is possible to develop operating practices that protect your initial investment, ensure that the water systems do not have a negative impact on quality or your production costs and also minimize your chance of having an environmental incident.
\end{abstract}

Keywords: Water; Management; Cost.

1 Chemical Engineering Technologist, Global Primary Metals Technical Consultant, Chemtreat, Grimsby, Ontario, Canada.

2 Metallurgical Engineering, Business Development Manager, Chemtreat, Vitória, ES, Brazil.

* Technical contribution to the $45^{\text {th }}$ Steelmaking Seminar, May $25^{\text {th }}-28^{\text {th }}, 2014$, Porto Alegre, RS, Brazil. 


\section{INTRODUCTION}

The challenge facing steelmakers today is maintaining or improving performance while reducing the "total cost of operation". The inflated costs of the past - excessive manpower, competitive supplier pricing - have, for the most part, been removed from today's costs. So, how can one be expected to realize further meaningful cost reductions? To accomplish this means to change.

The Steel industry is one of the largest industrial users of water. Whether one talks about a fully integrated mill or a mini-mill, many of the water systems have a direct impact on product quality, productivity and down time. When looking at all the contributing costs to making the final product, water costs are negligible. While a low cost, its impact on quality cannot be understated and its impact on the "total cost of operation" can be significant. Water can have a negative impact on production rates. The impact on quality is well understood and most steelmakers can share more than one example of quality problems directly attributed to the water quality. What is less understood or frequently not considered are the operating costs of the water systems, beyond the inherent chemical demands.

Today's quality steelmakers are surrounded by much equipment to meet the stringent demands of their customers. Whether it is additives to improve steel quality, ladle refining or degasifying and critical casting practices, water has a direct impact on most of these operations. Today's steelmakers use mold powders to achieve a high quality product and then must contend with its' negative impact on their equipment. Most of the capital expenditures incorporated in steelmaking are designed with water systems to protect this investment. Hence, while water itself may be a low cost commodity, it's' impact on operating costs can be very significant.

To operate water systems and ensure that they have no negative impact on product quality nor add to the "total cost of operation", while protecting the capital investment, may seem like a daunting challenge. However, when managed properly, the challenge is not that difficult and the rewards are well worth the effort.

Again, the cost of makeup water may be insignificant, but reducing the use of water should be part of our environmental commitment. And, the cost of treating the excess water and the potential problems it can create in managing the quality in all the water systems can be very significant.

To manage the water systems, one needs to focus on 5 key areas;

1 Team approach;

2 Equipment;

3 Operating practices;

4 Continuous monitoring tools to ensure identification of problems before they affect quality or operating costs;

5 The judicious use of chemicals to assist the above areas.

And, just as important, is the absolute need to meet the every stringent environmental restriction. A focus on the 5 key areas above will make meeting environmental guidelines much easier.

* Technical contribution to the $45^{\text {th }}$ Steelmaking Seminar, May $25^{\text {th }}-28^{\text {th }}, 2014$, Porto Alegre, RS, Brazil. 


\section{DISCUSSION}

\subsection{Team Approach}

Within most steelmaking operations there are 3 operating groups;

- Production team

- Utilities team

- Maintenance team

Often, these 3 groups work independently and interface only when there are production or quality problems. This is the first area where change may be necessary because:

- What the utilities team does with respect to their water quality can have a negative impact on production and quality of steelmaking;

- What the production team does can have a negative impact on the water quality;

- What the maintenance team "sees" can be like a "crystal ball" to the other teams.

So, as you can see, each team can help or can hinder the performance of the other team. Consequently, it is vital to all teams that there is a regular interface so that the teams are "friends" and not "enemies"... They are working "together" and not "independently".

\subsection{Equipment}

Within a modern steelmaking facility, there are many pieces of equipment:

- Cooling towers - remove heat;

- Filters - remove s.s., oils/greases;

- Heat exchangers - remove heat;

- Cooling panels - remove heat;

- Clarifiers - remove s.s., oils/greases;

- Sludge handling;

- Oil removal;

- Gas cleaning - environmental compliance, reuse of energy.

Equipment associated with water quality is designed to protect the steelmaking equipment (converter, molds, caster machine, etc.). And, while this is a significant capital investment, it is pale compared to the capital costs of the steelmaking equipment.

If not done recently, all the equipment should be audited to determine:

- the present performance compared to design;

- confirm if the equipment can meet the quality requirements;

- need for any repairs;

- need for additional/updated equipment.

* Technical contribution to the $45^{\text {th }}$ Steelmaking Seminar, May $25^{\text {th }}-28^{\text {th }}, 2014$, Porto Alegre, RS, Brazil. 

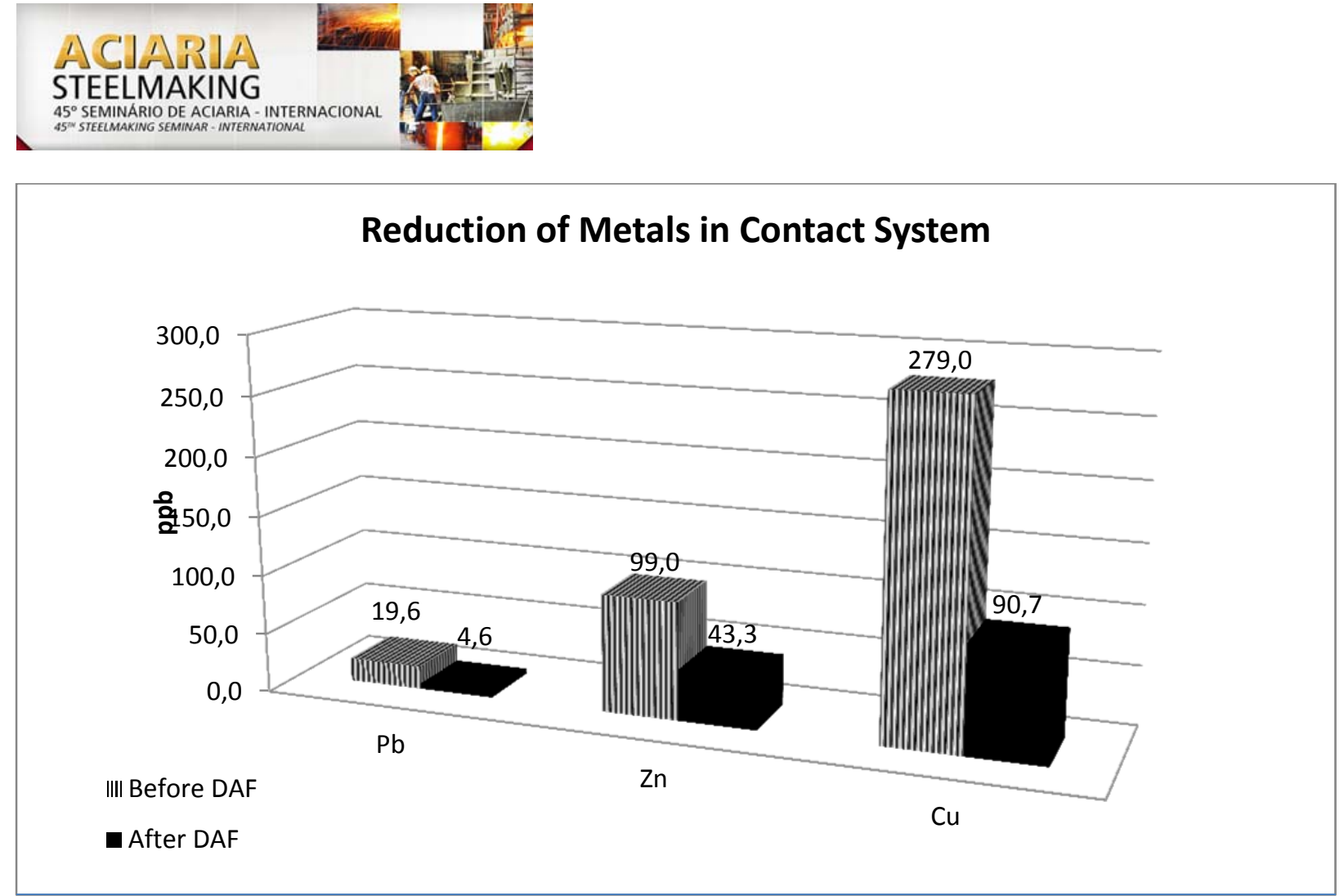

Figure 1. Reduction in Metals with DAF.

A DAF can effectively remove insoluble heavy metals by $>50 \%$ (Figure 1 ). Results will vary based on the particular heavy metal as well as the characteristics of the water being treated. Depending on these characteristics, some $\mathrm{pH}$ adjustment may be required.

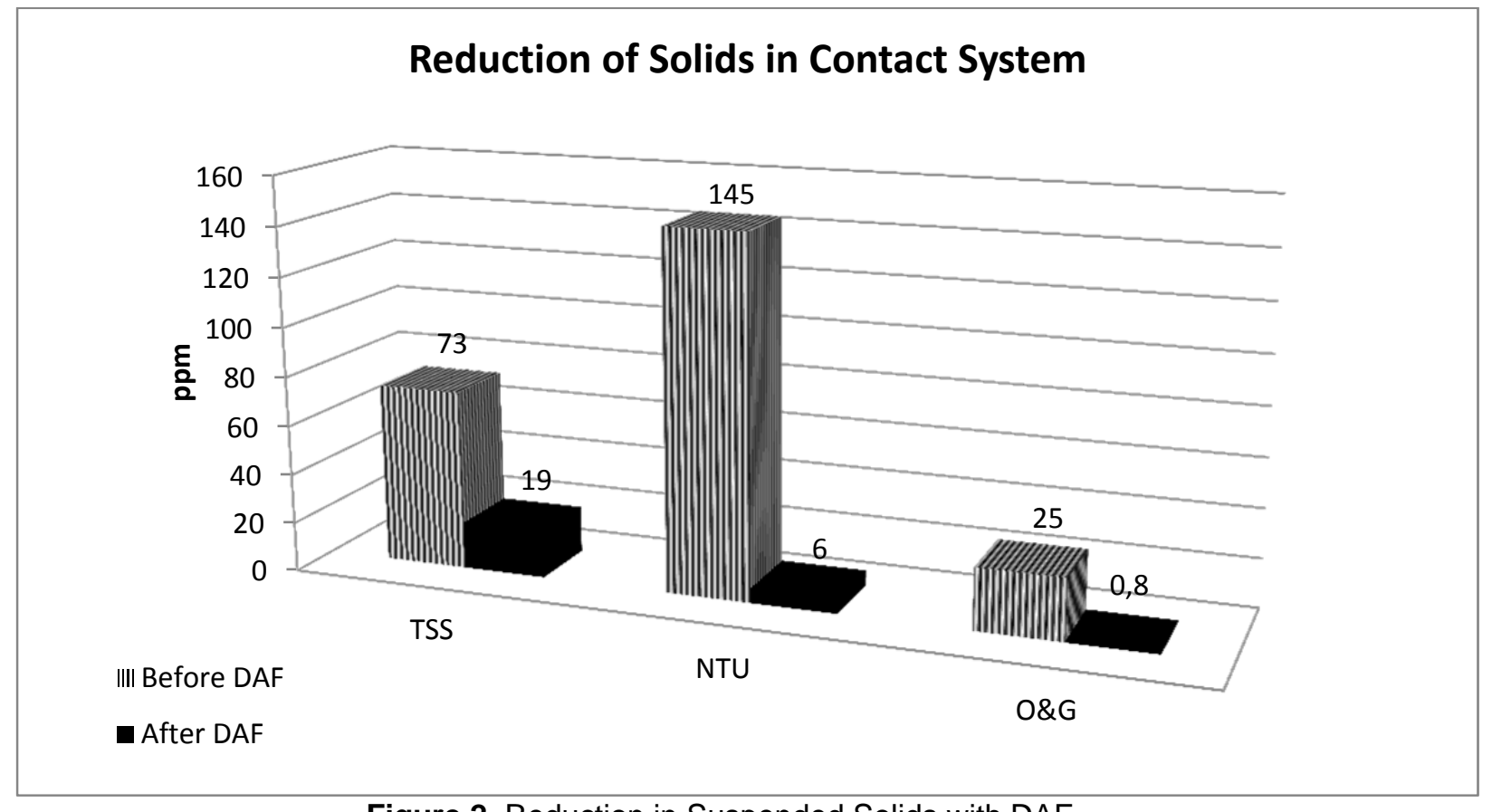

Figure 2. Reduction in Suspended Solids with DAF.

Suspended solids (including colloidal) removal can be improved significantly with a DAF. Improved oil and grease removal can be affected by the type (soluble/insoluble) of oil and grease and other characteristics of the water as showed in Figure 2.

* Technical contribution to the $45^{\text {th }}$ Steelmaking Seminar, May $25^{\text {th }}-28^{\text {th }}, 2014$, Porto Alegre, RS, Brazil. 
Poor performing equipment often results in higher continuing operating costs then a one-time repair cost.

Capital investment in new equipment can realize a higher gain in operating cost reductions than the initial capital investment.

\subsection{Operating Practices}

The equipment listed above are designed to work together - both individually and collectively - to supply the quality of water necessary to maintain production and quality. When this equipment is new and designed properly, this is usually not a problem. However, if we accept simply maintaining production and quality, then we cannot expect to achieve cost reductions. That is the challenge. This challenge can be met by modifying your present operating practices to enhance production and quality. Achieving this should provide a measurable reduction in the "total cost of operation".

As important as conducting an audit on all the water system equipment, an audit should also be done to identify all the users of makeup water and the destination of all the blowdown waters.

Some examples of operating practices:

- Water Usage

o Minimize use of extraneous water. Makeup water may not be add a significant cost to your operation, but the cost to treat the final effluent can be significant;

o Recycle "clean" water to a "dirty water system.

- Cooling Towers

o Maintain clean distribution decks and adjust flow evenly through all the cooling cells. This will ensure that the energy used to provide cooling (fans) is not wasted and cooling efficiency is maximized;

o Keeping access doors closed and repair faulty/missing louvers. This will reduce wasted energy and maximize cooling efficiency.

- Housekeeping

o Avoid using the caster scale pit as a convenient garbage pit. This will help to maximize spray water quality and reduce contaminants (oils, greases, heavy metals, etc.) in the effluent;

o Avoid sweeping excess mold powders below the mold (contaminate the spray water) to minimize corrosion in the spray chamber and fluoride contamination of the spray water.

- Mold Water Boxes

o Once the water boxes have been cleaned and readied for reuse, protect them from contamination from the storage environment. This will help to minimize particulate from fouling the cooling channels of the mold.

- Spray Chamber Evacuation System

o Make fan inspections part of your PM's to ensure proper air flow is maintained during production. This will help to remove water and acidic acids that contribute to corrosion problems with the spray chamber;

- Repair panels to ensure fans can remove the vapors as efficiently as possible and avoid higher corrosion in the spray chamber.

* Technical contribution to the $45^{\text {th }}$ Steelmaking Seminar, May $25^{\text {th }}-28^{\text {th }}, 2014$, Porto Alegre, RS, Brazil. 


\subsection{Proactive Monitoring}

There is no other area than this to emphasize the absolute necessity to a Team Approach. A steelmaker spent $>\$ 500,000$ US to clean a badly fouled machine cooling system (2.5 MT slab caster). With a proper proactive monitoring system, the fouling problems might have been identified prior to the need for a shutdown and expensive cleaning operation.

While there will be similarities from one steelmaking to another, it is also important to identify the differences and/or uniqueness of your systems.

Some examples of proactive monitoring:

- Hood Cooling Panels

o Regular use of infrared technology can help to identify tubes that are fouled, resulting in poor heat transfer.

- Side stream cartridge filters

o The use of simple and low cost cartridge filters can not only remove corrosion products that can foul these critical cooling systems, but by regular monitoring of the pressure drop they can serve as an early indication of water side problems before they affect system performance or quality.

- Caster Spray Chamber

o Maintaining photographic data (secured during normal downturns) of key areas can help to identify higher corrosion/fouling tendencies;

o Use of corrosion coupons (30- day exposure) can provide early warning of increased corrosion.

- Roll cooling

o Infrared technology and routine pressure/flow monitoring can help to identify cooling problems before they impact quality or operating costs.

- Sand filter

o Because there are usually several sand filters in use, when a performance problem begins to occur in one of the filters, the evidence of this in the spray water quality is muted until the problem becomes very significant. Routine monitoring of pressure drops and throughput can identify potential problems before they impact the spray water quality;

o Infrared technology can help to identify poor water distribution during normal operation and during backwash cycle.

\subsection{Chemical Treatment [1]}

When a steelmaker is looking at all his costs to produce steel, the chemicals associated with their water systems needs to be factored into the equation. If we look at some average costs in the industry according to the following criteria:

- Slab production - 2,000,000 tpy;

- Cost of Slab - \$400.00 US / tonne;

- Cost of water system chemicals - \$1,400,000 US/yr.(includes steam generation, Coke, BF).

* Technical contribution to the $45^{\text {th }}$ Steelmaking Seminar, May $25^{\text {th }}-28^{\text {th }}, 2014$, Porto Alegre, RS, Brazil. 

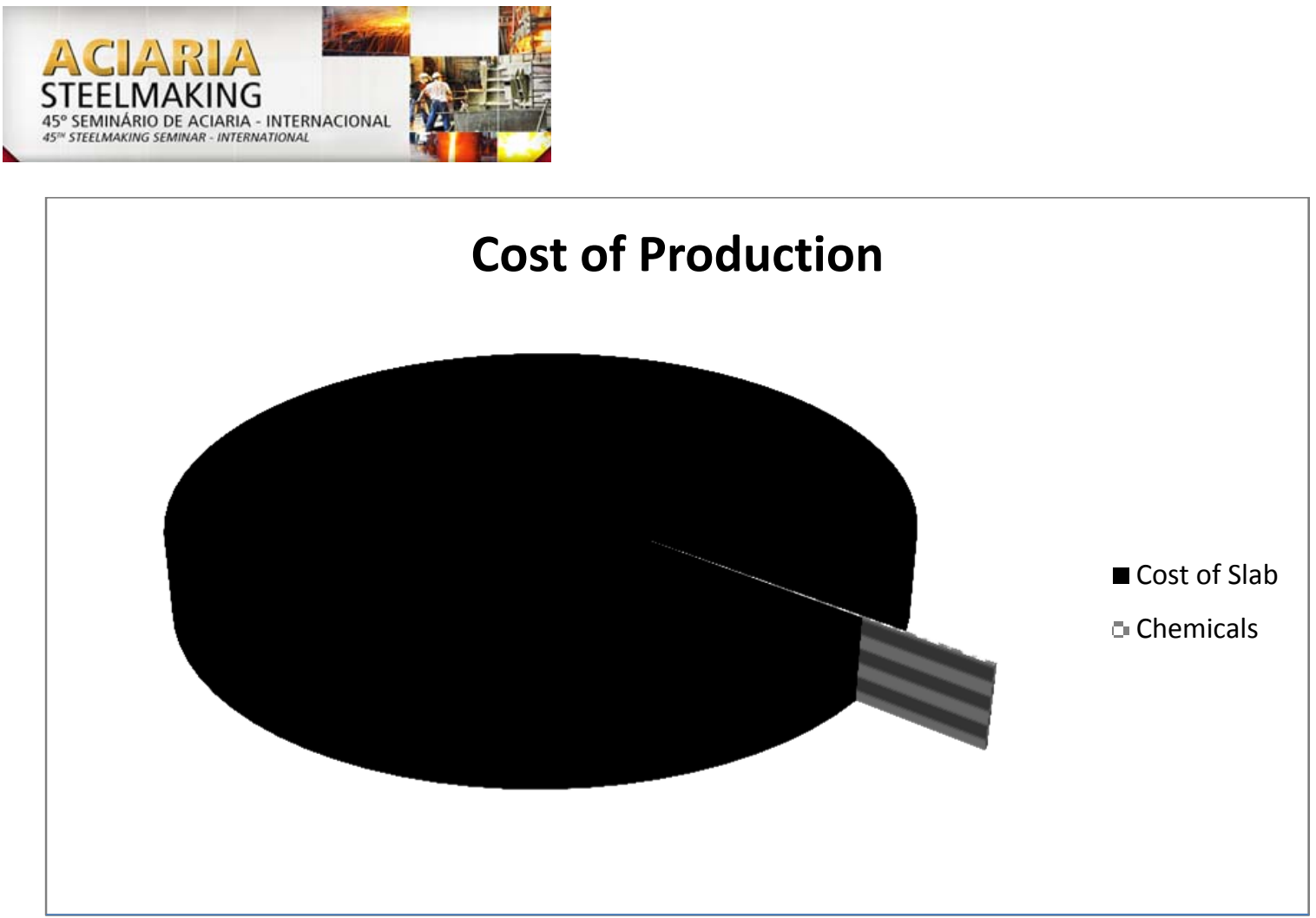

Figure 3. Chemical Cost Contribution to Cost of Slab.

The contribution of chemicals is only about $\$ 0.70 \mathrm{US} /$ tonne, which is approximately $0.175 \%$ of the total costs (Figure 3 ).

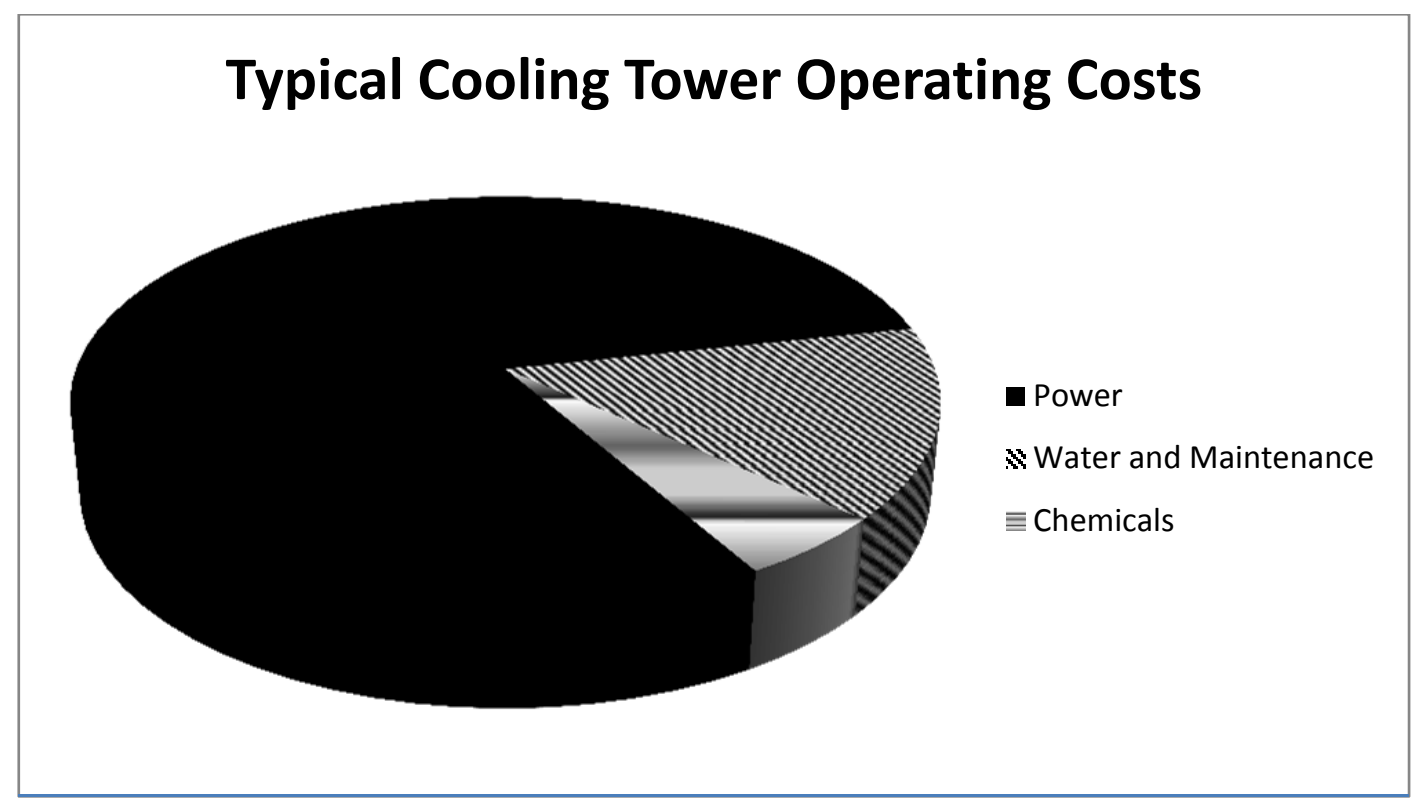

Figure 4. Cooling Tower Operational Costs.

Approximately $80 \%$ of the operational costs of a cooling tower is attributed by power Even with a traditional cooling tower, according to Diagnostic Cooling Solutions [2], the chemical costs generally represent only $5 \%$ of the total operating costs as showed in Figure 4.

As discussed earlier, water systems are a critical part of quality and performance and consequently can be a major contributor to the "total cost of operation" well beyond the actual chemical costs.

* Technical contribution to the $45^{\text {th }}$ Steelmaking Seminar, May $25^{\text {th }}-28^{\text {th }}, 2014$, Porto Alegre, RS, Brazil. 
Some examples of chemistry at work:

- Caster Spray Chamber

o Use of supplemental alkali $(\mathrm{NaOH}, \mathrm{Na} 2 \mathrm{CO} 3)$ fed to the bulk water or locally at the top zones can reduce the impact of acid attack from fluoride in the mold powders. Fed locally, a supplemental dispersant would be required to minimize scaling;

o When corrosion is due to chloride attack, switching from $\mathrm{NaClO}$ to $\mathrm{ClO}_{2}$ or $\mathrm{H}_{2} \mathrm{O}_{2}$ can help reduce chloride levels.

- OG Sludge Handling

o Polymers can condition the sludge to improve dewatering and enhance the filtering performance (throughput).

- Scale Pit

o Polymers and emulsion breakers can enhance oil/grease and solids removal.

- Filters

o Surfactants used in the backwash cycle can improve cleaning of filter media.

- Segment Cleaning

o Specialty chemicals coupled with a designed specific cleaning procedure can ensure critical roll cooling is maintained [3].

\section{CONCLUSION}

The water you bring into your systems is not a significant cost to your total cost of production. However, once you have accepted it, then the potential costs to your operation can be very significant. And what your processes add to the water takes the water from an environmentally friendly situation in the makeup to an absolute need to return it to an environmentally friendly condition prior to discharge.

In summary, to manage the water systems you need to focus on all the 5 key areas;

1. Team approach;

2. Equipment;

3. Operating practices;

4. Continuous monitoring tools to ensure identification of problems before they affect quality or operating costs;

5. $\quad$ The judicious use of chemicals to assist the above areas

Whether you develop an in-house team for your water management or you use the services of market suppliers, the benefits can be significant. You can lessen your reliance on world steel prices - reduce the impact on your profit when prices are down and increase your profit when prices are rising.

This may seem like a daunting task. This may seem like a significant time commitment. Neither can be farther from the truth. It is a change. And, change is always difficult. But, once embraced, this change can improve performance, improve quality, improve productivity, reduce the "total cost of operation" and provide a more proactive approach to environmental compliance.

* Technical contribution to the $45^{\text {th }}$ Steelmaking Seminar, May $25^{\text {th }}-28^{\text {th }}, 2014$, Porto Alegre, RS, Brazil. 


\section{REFERENCES}

1 The Steel Industry Water Conference; 12th-14th September 2012; Clearwater Beach, USA [access: $26^{\text {th }}$ Nov. 2003]. Available at: http://www.chemtreat.com/seminars/steelindustry-water-conference/.

2 Diagnostic Cooling Solutions Inc. - Performance Metrics [access: $26^{\text {th }}$ Nov. 2013]. Available at: http://www.diagnosticcooling.com/OverviewWhyPerfMet.htm.

3 Hulings C. Machine Roll Maintenance Cleaning. In: ChemTreat Steel Industry Water Conference; 2012; Miami, USA. SMS Millcraft; 2012.

* Technical contribution to the $45^{\text {th }}$ Steelmaking Seminar, May $25^{\text {th }}-28^{\text {th }}, 2014$, Porto Alegre, RS, Brazil. 